\title{
Feedback Provision and Learner Achievement in Mathematics in Secondary Schools in Nairobi County, Kenya
}

\author{
George Otieno Asewe ${ }^{1, ~ *, ~ J a p h e t h ~ O d o d a ~ O r i g a ~}{ }^{2}$, Peter Kyalo Mulwa ${ }^{2}$ \\ ${ }^{1}$ Department of Psychology, University of Nairobi, Nairobi, Kenya \\ ${ }^{2}$ Department of Educational Communication and Technology, University of Nairobi, Nairobi, Kenya
}

Email address:

george2sewe@yahoo.com (G. O. Asewe), ododaoriga@uonbi.ac.ke (J. O. Origa), peter.kyalo@uonbi.ac.ke (P. K. Mulwa)

${ }^{*}$ Corresponding author

\section{To cite this article:}

George Otieno Asewe, Japheth Ododa Origa, Peter Kyalo Mulwa. Feedback Provision and Learner Achievement in Mathematics in Secondary Schools in Nairobi County, Kenya. International Journal of Secondary Education. Vol. 8, No. 4, 2020, pp. 110-114. doi: $10.11648 /$ j.ijsedu.20200804.11

Received: September 19, 2020; Accepted: October 7, 2020; Published: October 20, 2020

\begin{abstract}
Feedback remains the mainstay in Assessment for learning. However, feedback stands effective most when given in time, and when is firmly knotted to standards regarding prospects and comprises exact proposals for how to upsurge future achievement and meet education goals. This research was undertaken to investigate the effect of effective feedback provision on learner's mathematics achievement. The research was quasi-experimental and a pretest/posttest control group design was used. The sample constituted 80 form three learners which were clustered as control as well as experimental groups in the same way. The groups were both pre-tested. The group that was experimental was well taught and the feedback was given as required by Assessment for Learning (AFL) during treatment and the control group wasn't given feedback throughout the treatment. The pretest before the intervention of the variable had a mean score of $25.7 \%$ while after the intervention of the effective feedback provision, the mean score was $56.4 \%$. This shows an improvement a positive of $30.7 \%$. The mean score for the controlled group was $24.4 \%$ for the pretest and $24.2 \%$ for the posttest which was a fall of $0.2 \%$. In comparison to the experimental group, there was a greater improvement than a control group. A conclusion was reached that effective provision of feedback has a positive effect on learner achievement in mathematics.
\end{abstract}

Keywords: Feedback, Learner's Achievement, Mathematics

\section{Introduction}

As a result of the position and placement of mathematics in the society and its role in logical thinking desired today in the $21^{\text {st }}$ century, and the fact that its achievement regarding academic attainment is low as indicated in Kenya National Examinations Council (KNEC) report [12], it is necessary to review and find a way of reversing this effect. It is believed that rethinking assessment to Assessment for Learning (AFL) that leads to feedback which is related to the new thinking will result in increased and improved mathematics achievement. Feedback is some response given to a learner depending on their achievement. For instance, informing learners about test scores is a kind of feedback [14]. Feedback is key to assessment for learning, but not all feedback is effective. Feedback remains the backbone of Assessment for learning. However, feedback stands effective most when given in time, and when remains tightly tied to standards concerning prospects and includes exact proposals on how to increase the forthcoming achievement and meet schooling goals [11]. The most significant way to motivate learners is through feedback provision. In the words of Carless and Boud, provision of feedback empowers learners to assess own work and improve their learning [5].

Formative response is contributory in a learner's education experience. It is effective if it is timely, personal, motivational and manageable, and relates to assessment criteria. In spite of its importance, research however shows that learners are discouraged from involving in the process of feedback because of reasons related to absence of motivation 
including difficulty to relate and reflect on the comments of the feedback [4]. Getting feedback is intrinsically related to feeling. This is true particularly within the circumstance where depraved action wherever learners could feel discontentment, anxiety, guilt, discouragement, lack of authority and confusion. Consequently, for the teacher to engage learners in feedback process, one must take into account learners' tactics and feelings for exciting motivation. The main challenge when utilizing some formative feedback scheme is the quantity of time needed to constitute that feedback. Producing personalized, timely, and detailed feedback requires substantial effort and time, particularly for classes that are large. Weighty workload on teachers and an amplified learner numbers can result to insufficient information and may jeopardize the value of the feedback. Conversely, feedback is fundamental to learner learning. Therefore, efficient and innovative tools that can support the instructor in the action of AFL are necessary. Nevertheless, thorough feedback and tailored comments require a lot of manual labor. Reducing the teacher's workload is also very essential [10].

The feedback from assessment for learning is utilized to adjust learning as well as teaching to meet the learner's needs. When instructors understand the learner's progress, they will be able to modify instruction method including as re-teaching, experimenting other teaching approaches or providing varied practice opportunities. These actions can result to better learner's mathematics achievement. Assessment for learning doesn't add to final score awarded for the content area; instead it backs learning via feedback provision. It pinpoints what is decent about some piece of tasks and the reason why it is good; it also shows what is not worthy and how it can be improved. Formative feedback dictates what the learner and the instructor should do subsequently. In AFL we assess the learners' achievement and rectify them in a situation where there is some deviation. The outcomes of AFL are not used to judge whether the learners have passed or failed. Leaners may hide their dimness if this is done and the aim of AFL may not be realized [7].

Balan in his research revealed that learners believe that feedback is very effective when ascertaining dissimilar ways of solving and presenting problems [1], while some scholars nevertheless, remained more earmarked about the practice. Effective feedback is perceived as being positive, timely, and specific. Real feedback aids in clarifying education goals to learners, communicates learning purpose so that schoolchildren become highly motivated. Such kind of feedback helps pupils identify their strengths, improvement areas, and subsequent steps in their learning. Additionally, feedback provides the educators with information to aid in modifying their teaching. Feedback plays an important function in enhancing and building learners' learning motivation [2].

The main challenge when utilizing every formative feedback scheme is the insufficient time required to implement it. Producing personalized, timely and detailed feedback requires substantial effort and time, particularly for classes that are large. Weighty workload on teachers and an amplified learner numbers can result to insufficient data and may compromise the feedback's value. Conversely, feedback is fundamental to learner learning. Therefore, efficient and innovative tools that can support the instructor in the action of AFL are necessary. Nevertheless, thorough feedback and tailored comments require a lot of manual labor. Reducing the teacher's workload is also very essential [10].

The National Council of Teachers of Mathematics (NCTM) Standards [16] quoted that reasoning is necessary in learning mathematics and involves examining mathematical patterns to see if any generalizations can be made based on an emerging pattern. Based in their own explorations, learners need to make conjectures about any generalizations they might see and test those conjectures. Meanwhile, learners should discuss their reasoning with others regularly and explain their rationale for making those assertions. This is a vital portion of mathematics learning so as to understand [9]. Because of the longitudinal character of the development of these skills, it is important to create a classroom environment that is conducive to these kinds of discussion as a regular part of the classroom. In the application of any mathematics learning activity, it is very important for educators to develop their ideas about the meaning of mathematics teaching in a way that they can support the process standards within their classrooms every day. The importance of a classroom environment to stimulate and develop productive classroom discourse cannot be stressed enough; it is not enough to give the learners activities and let them "loose on the activity."

Mathematics success is measured in different ways. The blame for dismal mathematics achievement has been on instructors for not having adequate skills. Internationally, an institute with better achievement will receive more rewards such as funds and other assets such as learning materials and textbooks than a school with poor achievement. Moreover, a better performing school will receive adequate highly skilled and experienced teachers than a poor performing school. The school time table should be designed in such a way that it gives slow learners more time to master the mathematics concepts and keeps the fast learners busy. Educators need to develop math interest in learners at an early age by incorporating more practical and concrete skills. This makes the future math achievement better.

\section{Methodology}

\subsection{Research Design}

This research work employed descriptive quasiexperimental design, utilizing pretest and posttest equivalent group. Quasi-experimental design in form of pretest-posttest for experimental group and control group was administered to test if effective provision of feedback to learners had an effect on their mathematics achievement. Kothari and Garg stipulate that the benefit of pretest-design is that it permits many comparisons [13]. The pretest was given to 80 form 
three learners in the first week and the posttest was given to the same group in the third week of the second term after teaching the experimental group using feedback provision one of the two selected schools. During the teaching the learners were allowed to give their own feedback and the researcher also provided his feedback to an experimental group. The pretest and posttest were in form of questions from surds and commercial arithmetic II respectively. The first topic tested (surds) was selected because all the learners had covered it in their previous learning. The second topic (commercial arithmetic II) was chosen because all the learners had not been taught from that topic. The questions summed up to forty marks each and the scores from the tests were compared to see if there was some difference after feedback provision which was the intervention.

\subsection{Target Population}

Mugenda \& Mugenda define population as the amount of objects having the favored features, generating the study creation [15]. The target population comprised of secondary schools owned by the government in Nairobi County while study population were form three learners from two public secondary schools in the same County. As per Kenya's ministry of education, 172 is the number of secondary schools in Nairobi County with each school having an average of 28 teachers (principals, deputy principals and teachers) contributing to 2016 teachers and 25,800 form three learners.

\subsection{Sampling Design, Validity and Reliability}

The researcher adopted purposive sampling technique to select three public secondary schools with an average achievement in mathematics. Two schools with a total of 120 learners were involved in the study. The study used both face and content validity to ascertain the validity of the tests. Test re-test technique in third school that was not for the study was used to estimate the reliability of the tests.

\subsection{Data Collection Procedure and Ethical Considerations}

The researcher got the authorization to perform the study from the University of Nairobi's head of psychology department, the National Commission for Science, Technology and Innovation (NACOSTI), Nairobi County officer of education, the Kamukunji sub-county officer and the selected secondary school's head teachers and proceeded to carry out the research. The Statistical Package for Social Sciences (SPSS version 11.5) and excel 2013 were used to analyze the data and ethical considerations were observed by not to exposing the identity of the schools or the learners used for the study.

\section{Results}

The study's purpose was to determine the effect of feedback provision on learner's mathematics achievement in public secondary schools in Nairobi County, Kenya. Out of 80 form three learners targeted to be given the pretest, 40 did the pretest while 36 did the posttest. The 4 learners who never did the posttest were claimed to have been sent home for school fees, indiscipline cases or just absent for unknown reasons. These rates were considered passable for data examination because they exceeded $85.0 \%$ return rate as recommended by Mugenda \& Mugenda [15]. Figure 1 shows the learners' achievement in pretest as well as posttest. The researcher conducted the tests to the learners on specific areas of concern which include surds and commercial arithmetic II in pretest and posttest respectively. Posttest was given after the researcher had taught for two weeks in the two selected schools using effective feedback provision.

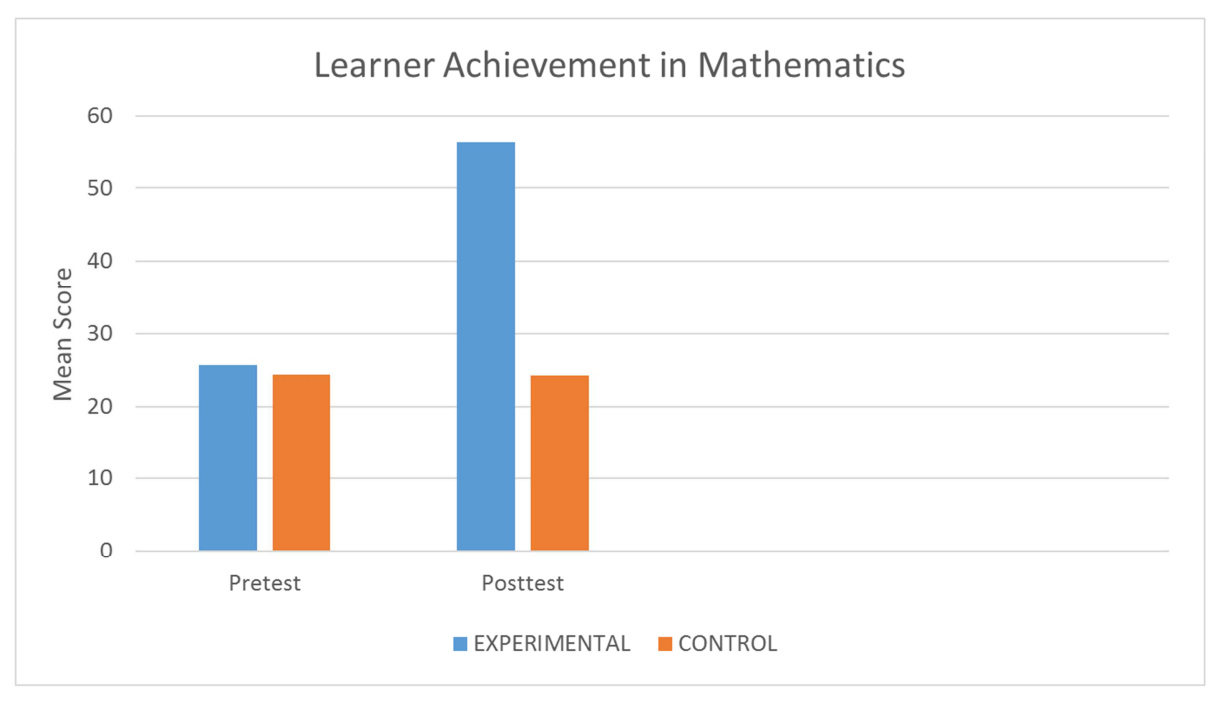

Figure 1. The learner's achievement in posttest and pretest.

The researcher calculated the mean score of learners to find the average score. The pretest before the intervention of the variables had a mean score of 6.425 while after the intervention of the effective feedback provision, the mean 
score was 14.1. This shows an improvement of +7.675 . The mean score for the controlled group was 6.1 for the pretest and 6.05 for the posttest which was a fall of 0.05. In comparison to the experimental group, there was a greater improvement than a control group. This is an indication that feedback provision has a positive impact on learner's achievement in mathematics. This supports Centre for Educational Research and Innovation (CERI) argument that feedback is important to Assessment for Learning (AFL) [6]. However, not every feedback is efficient. Feedback is supposed to be precise and timely and contain proposals on how to improve forthcoming attainment. Feedback is supposed to be positive so as to motivate the learners to continue learning. A negative comment or attitude in feedback provision may kill a healthy atmosphere for the classroom which can result to poor achievement in a subject area.

The posttest for both the groups were compared as shown in figure 2 .

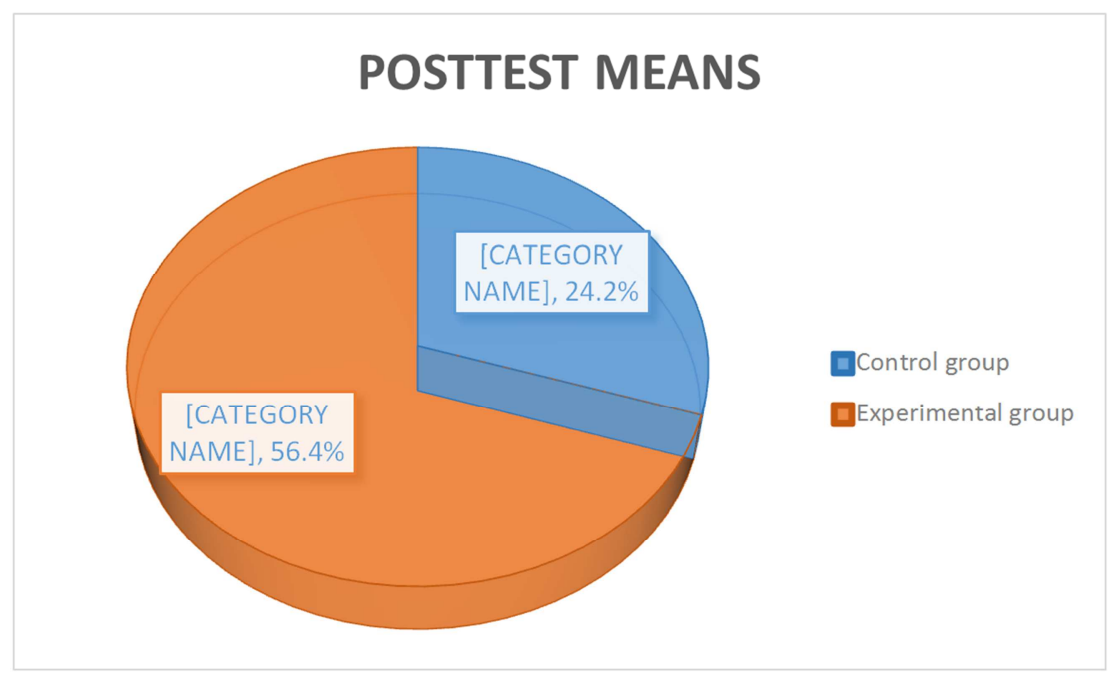

Figure 2. Posttest means for control and experimental groups.

According to figure 2, the experimental group showed a significant improvement with a mean of $56.4 \%$ than a control group with a mean of $24.2 \%$. This is in agreement with Bruno \& Santos who cited that one technique to support learners' learning is by making use of effective feedback practices [3]. They further stated that feedback is treated as a method of AFL and is one of the most serious influences on learner learning because it is utilized in helping learners recognize cracks in their knowledge and to provide them with the next steps in filling those gaps.

\section{Discussion}

In relation to the main goal of this research which was to examine the effect of feedback provision on learner's achievement in mathematics in Kenyan secondary schools, the outcomes are conclusive. The learners that took part in the intervention process showed improved achievement in the posttest. Fisher \& Frey opines that providing feedback helps learners feel that their teacher is supportive and caring of their own learning [8]. In this manner, learners get motivated intrinsically. They further support the findings that feedback affect learner achievement and is ranked as the strongest intervention at educator's disposal. In pre-test exam, both clusters had the same mean scores (Figure 1). Similar observations were made after changing the group for intervention with selection of a new topic. After feedback provision, different results were obtained for the experimental group. Teachers are required to know feedback provision as well as teaching learners in making use of their own feedback. This will make learners more focused as they come to know their learning purposes. Feedback plays an important role in enhancing and building learners' motivation to learn a particular content area [2].

\section{Conclusion}

Based on the findings which indicate a significant improvement in learners' scores after intervention of feedback provision from $25.7 \%$ to $56.4 \%$ which is an increase of $30.7 \%$, the study can evidently conclude that feedback provision has a positive effect on learner's achievement in mathematics in secondary schools in Kenya. It can be concluded that effective feedback provision can significantly increase a learner's motivation and his/her strategy to revise more. This implies that learners will be motivated to study more. For reasonable learning to happen, instructors must deliver feedback wrapped in a way that makes sense and also allows learners to rectify their fallacies. Good rehearsal, should therefore help differentiate between low and high achievers [17].

\section{Recommendations}

Grounded on the discoveries of the study, the research recommends that teachers need to be supported by the school 
authority and parents in order to get enough resources for effective feedback provision. It is also suggested that the content of the syllabus should be reduced so that the pressure to teach for purposes of preparing learners to pass tests can be reduced. This will further ensure that teachers have sufficient time to provide decent feedback to learners. The study further recommends that decent feedback requires being tied to a clear criteria concerning prospects for schoolchildren's achievement and this makes learning practice more modelling and transparent. The function of AFL isn't accreditation. The research therefore advices educators to provide straight feedback concerning teaching and learning processes in order to improve learners' achievement in any subject area. The study further recommends that the same research can also repeated in the same county in order to identify the reliability of the results that revealed the positive impact of feedback provision in mathematics. The study can also be repeated with other subjects in other counties or the whole country.

\section{References}

[1] Balan, A. (2012). Assessment for learning: A case study in mathematics education. Malmö: Faculty of Education and Society, Malmö University.

[2] Bettney, E., Wu, Y. \& Cheng, L. (2014). Assessment and Motivation: Perspectives from Teacher Candidates Paper. June 2014. Kingston, ON K7M 5R7. Canada.

[3] Bruno, I. \& Santos, L. (2010). Written comments as a form of feedback. Studies in Educational Evaluation, 36, 111-120. https://doi.org/10.1016/j.stueduc.2010.12.001.

[4] Burke, D. \& Pieterick, J. (2010). Giving students effective written feedback. Berkshire, England: Open University.

[5] Carless, D. \& Boud, D. (2018). The development of student feedback literacy: enabling uptake of feedback. Assessment \& Evaluation in Higher Education, 43: 8, 1315-1325. DOI: 10.1080/02602938.2018.1463354.
[6] Centre for Educational Research and Innovation (CERI). (2008). Assessment for learning - the case for Formative assessment. OECD/CERI international conference "Learning in the 21st Century: Research, Innovation and Policy".

[7] Dandekar, P. D. (2015). Effects of Formative Assessment of Students on their Academic in Department of Kriya Sharir. Journal of Education Technology in Health Sciences, 2 (2), 51-56.

[8] Fisher, D. \& Frey, N. (2009). Feed up, back, forward. Educational Leadership, 67 (3), 20-25.

[9] Fonkert, K. (2010) Student Interactions in Technology-rich Classrooms. Mathematics Teacher, v104 n4 pp. 302-307.

[10] Hatziapostolou, T. \& Paraskakis, I. (2010) "Enhancing the Impact of Formative Feedback on Student Learning through an Online Feedback System". Electronic Journal of $e$ Learning Volume 8 Issue 2 2010, (pp 111-122), available online at www.ejel.org.

[11] Herman, J. L. (2010). Coherence: Key to next generation assessment success (CRESST Policy Brief). LoS Angeles, CA: CRESST.

[12] Kenya National Examinations Council (KNEC). (2017). The Year 2017 KCSE examination Report. Volume 2: Mathematics \& Science. The Kenya National Examinations Council.

[13] Kothari, C. \& Garg, G. (2014). Research Methodology Methods and Techniques. 3rd ed. New Delhi: New Age International (P) Ltd., p. 63.

[14] Lee, C. (2006). Assessment for Learning in Mathematics. Open University Press.

[15] Mugenda, O. \& Mugenda, A. (2003). Research Methods: Quantitative \& Qualitative Approaches. Acts Press, Nairobi.

[16] National Council of Teachers of Mathematics (NCTM). (2014). Principles to actions: Ensuring Mathematics success for all. Reston, VA: NCTM.

[17] Nicol, D. J. \& Macfarlane-Dick, D. (2006). Formative assessment and self-regulated learning: A model and seven principles of good feedback practice. Studies in Higher Education, 31, 199-218. doi: 10.1080/03075070600572090. 